\title{
Laboratórios Abertos: Encontros artístico-pedagógicos com o grupo Yuyachkani
}

\author{
Open Laboratories: \\ Artistic-pedagogical meetings with Yuyachkani group
}

Ana Carolina Fialho Abreu ${ }^{1}$

Paola Lopes Zamariola ${ }^{2}$ 


\section{Resumo}

No presente artigo, pretendemos discutir algumas experiências artísticas e pedagógicas, realizadas pelo grupo peruano Yuyachkani em seus Laboratórios Abertos. Realizados há mais de uma década, é possível diagnosticar em suas proposições, uma constante investigação com relação à possibilidade de reativação da potência política da arte na atualidade. Tais laboratórios são compostos por espetáculos, demonstrações de trabalhos, mesas de debates, oficinas, treinamentos e experimentos cênicos realizados anualmente ao longo dos oito primeiros dias do mês de agosto. Neste intenso período, os/as artistas realizam férteis intercâmbios com criadores/as e investigadores/as, que se propõem a tal imersão, na sede do grupo, na cidade de Lima.

Palavras-chave: América Latina; cena contemporânea; práticas artístico-pedagógicas; laboratório aberto; Yuyachkani

\section{Abstract}

In this article, we intend to discuss some artistic and pedagogical experiences, carried out by the Peruvian group Yuyachkani in their Open Laboratories. Made more than a decade ago, it is possible to diagnose in its propositions, a constant investigation regarding the possibility of reactivation of the political power of art in the present time. These laboratories are composed of shows, demonstrations of works, discussion tables, workshops, trainings and scenic experiments performed annually during the first eight days of August. In this intense period, artists make fertile exchanges with creators and researchers, who propose to immerse them selves, in the group's head quarters, in the city of Lima.

Keywords: Latin America; contemporary scene; artistic and pedagogical practices; open Laboratory; Yuyachkani

\footnotetext{
Professora de Artes do Instituto Federal de Minas Gerais, Campus Ouro Preto. Doutoranda do Programa de Pós-Graduação em Artes Cênicas da Universidade Federal da Bahia com Co-tutela no Programa de Pós-Graduação em Ciências Sociais/Antropologia da Universidad Nacional Mayor de San Marcos/Peru. anacarolinaabreu1886@gmail.com

2 Doutoranda do Programa de Pós-Graduação em Artes Cênicas (PPGAC) - Universidade de São Paulo (USP). paola.lopes.zamariola@gmail.com
} 


\section{Estou pensando, estou recordando}

No final do século XX, uma parte importante das Artes Cênicas na América Latina, esteve marcada pela renovação da atenção para a responsabilidade política do/a artista, direcionando desse modo muitas de suas experiências ao ativismo e às estratégias de resistência nas artes. Tratam-se de práticas que buscaram se sustentar na ação independente, à margem dos mecanismos e discursos de poder, almejando interferir principalmente contra as naturalizadas práticas, ligadas à violência e ao esquecimento. No prólogo do livro El Cuerpo Ausente: performance e política (2008), de Miguel Rubio Zapata, diretor do grupo cultural peruano Yuyachkani, a pesquisadora cubana-mexicana Ileana Diéguez Caballero, afirma que frente ao horror, a impiedade, aos diversos sistemas de reclusões e desaparecimentos forçados, praticados pelos regimes totalitários e pelas ditaduras militares que marcaram o nosso continente, desde perseguições, desaparecimentos, torturas e matanças, diversos/as artistas e grupos encontraram na arte um canal para que a memória não fosse apagada, e para que se trouxesse à tona, a presença de corpos e vozes ausentes.

Neste contexto, em 1971, na cidade de Lima, surge o Yuyachkani, que desde então segue emprestando seus corpos para a recuperação de tantas histórias silenciadas. Nas poéticas e políticas dos/as artistas que integram o grupo, o corpo é suporte de ações que objetivam elaborar atos éticos que façam visíveis os corpos ausentes de um ethos coletivo. Segundo Miguel Rubio Zapata (2008, p. 37) com a violência que assolou e devastou o país, entre maio de 1980 e novembro de 2000, os/as atores e atrizes do grupo que antes haviam tido como centro de trabalho a presença - um corpo presente, novo, atento, decidido, dilatado e memorioso - tiveram que trabalhar a ausência em si mesmos/as, para evocar os corpos dos/as ausentes.

Desta forma, através de processos construídos sobre os pilares da memória, e a partir do diálogo com os sujeitos implicados na realidade peruana, a criação cênica do grupo se estabelece como uma prática primordialmente relacional, podendo então, ser uma forma de interstício social (Diéguez, 2008, p. 25). Assim, a presença de corpos e vozes invisibilizados, não apenas se refere a uma especificidade material, uma fisicalidade do ator e da atriz que executam uma partitura performativa, mas sim, a presença que abarca a ética do ato, a responsabilidade de estar em um espaço cênico ou público, assumindo a intervenção como persona-artista-cidadão de seu tempo, com todos os riscos que se assume ao manifestar-se politicamente nesses espaços.

Nos cenários atuais, o Yuyachkani tem colocado em ação, através de imagens e relatos, diferentes estratos da memória peruana, tensionando desta maneira o compromisso com as problemáticas das distintas comunidades que compõem a história do País. Ao promover criações que potencializam rituais coletivos, se tornam tênues as fronteiras entre arte e vida, entre ficção e realidade, entre ator/atriz, performer e cidadão/cidadã, explicitando a dimensão ética de todo o ato estético e a realização de práticas artísticas como forma de ativismo social.

No artigo O grande teatro de Paucartambo (2016), Miguel Rubio Zapata chama atenção para o fato da história peruana, assim como a de outros países da América 
Latina, ser marcada por diversos momentos nos quais práticas culturais, rituais, espirituais e artísticas foram proibidas, punidas e excluídas. Neste texto o diretor frisa, por exemplo, a violência com a qual "o teatro europeu foi imposto na América desconhecendo as formas de representação que habitavam nessas terras" (Zapata, 2016, p. 06), destacando que

durante o período colonial, muitas formas de representação pré-hispânicas foram moldadas de acordo aos parâmetros do teatro ocidental. Os "gêneros" autóctones encontrados pelos conquistadores foram definidos, como já mencionado, a partir de um cânone cultural ocidental, e muitas daquelas práticas foram proscritas com argumentos teológicos, convergentes com as necessidades da conquista e da dominação" (Zapata, 2016, p. 11).

Contudo, essas formas seguem vivas, cruzaram o tempo com as mitologias que as sustentam e constroem acontecimentos efêmeros que evocam, segundo Zapata (2011, p.19), maneiras ancestrais de "representação". O grupo reconhece desta maneira, as identidades inclusivas, onde se encontram elementos de uma América pré-hispânica e acolhe elementos das práticas cênicas contemporâneas. Nos alerta o diretor, que a América Latina e o Caribe não são apenas um, são indígenas, africanas, europeias e contemporâneas e que o teatro realizado por eles/as "recorre el espíritu de los tres continentes y se alimenta culturalmente de esas tres raíces, y com ellas dialoga en igualdad de condiciones con los teatros de todo el mundo" (Zapata, 2011, p.19).

Desta maneira, observamos que no grupo Yuyachkani coexistem em paralelo múltiplas diferenças artísticas e culturais, que não se fundem, mas se antagonizam ou se complementam. Uma mescla, não isenta de conflito, que conjuga opostos sem subsumir um em outro, uma justaposição de diferenças concretas que não tendem a uma comunhão desproblematizadora, constituindo imagens poderosas para pensar a coexistência de elementos heterogêneos.

\section{Laboratórios abertos e suas acumulações sensíveis}

Através destes elementos, é possível diagnosticar na trajetória do Yuyachkani, que está em diálogo com outras agrupações de artistas latino-americanos, que os espetáculos não são a totalidade, muito menos a prioridade de seus criadores/ as. A criação cênica é apenas uma das dimensões dos trabalhos desenvolvidos, que também encontra na fruição e na formação, desdobramentos fundamentais de suas poéticas. Neste sentido os Laboratórios se organizam como espaço de resistência e de fortalecimento de redes de criadores, criadoras, cidadãos e cidadãs que almejam interferir nas esferas públicas de suas cidades e países.

Como fazem anualmente desde 2008, nos oito primeiros dias de agosto, o Yuyachkani realiza seu Laboratório Aberto, um encontro artístico-pedagógico, através de um explícito convite à imersão e ao convívio (ver figura 1). 


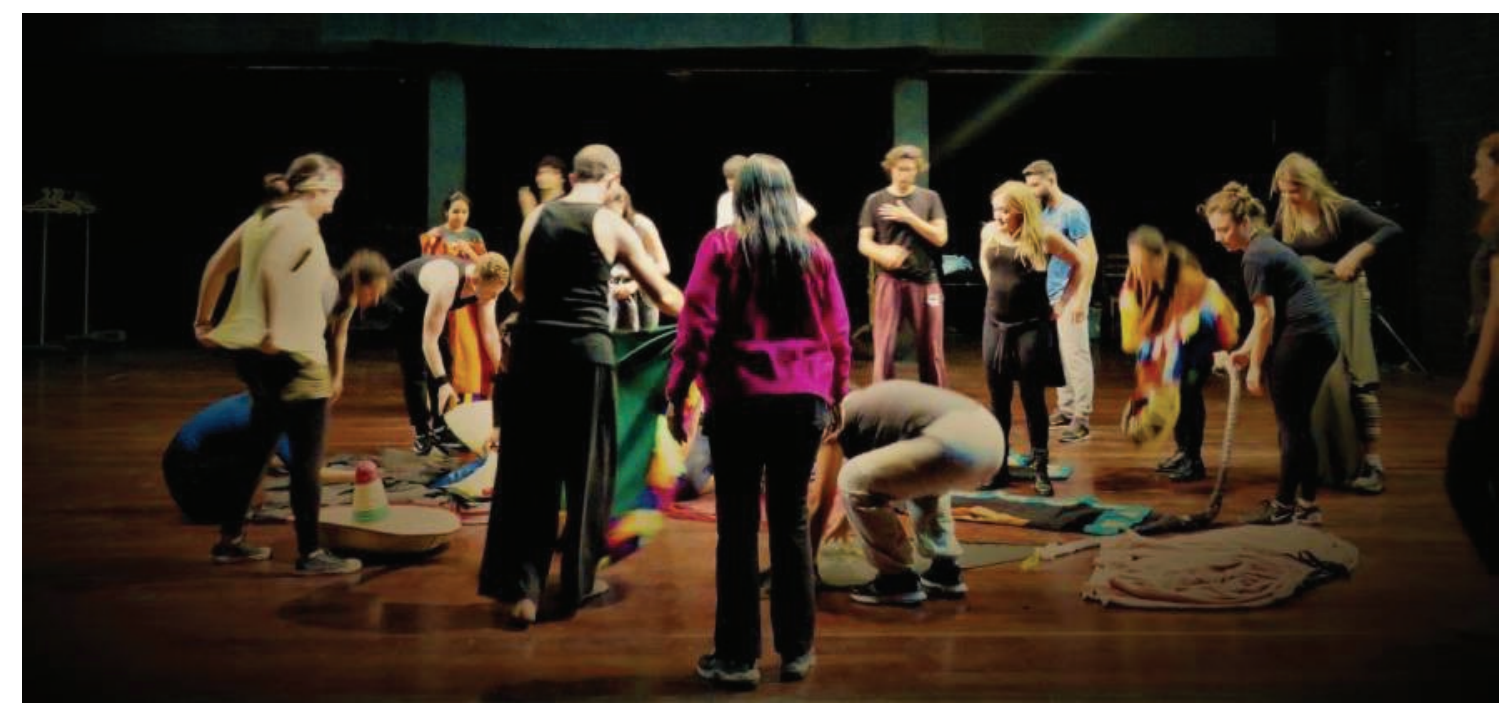

Figura 1- $9^{\circ}$ Laboratório Aberto- Encontro Pedagógico do Grupo Yuyachkani. Fonte: Claudia Vanesa Figueroa. Data: 09 de agosto de 2017.

Ao longo do Laboratório Aberto, os/as participantes acumulam sensivelmente em seus corpos, as experiências de trocas, diálogos e treinamentos, mediados por diferentes atrizes e atores do grupo. Bastante presente na poética do Yuyachkani, o processo criativo da acumulação sensível, serve de inspiração para se analisar a constituição de práticas da cena latino-americana, que tendem a despriorizar o elemento verbal para assim elaborar dramaturgias expandidas, nas quais as escrituras cênicas não se centram somente no discurso, mas também nas suas materialidades, visualidades e sonoridades.

Para poder conceituar a noção de acumulação sensível, e tentar compreender quais mutações de sentidos ela vem sofrendo na trajetória do grupo, recorremos a algumas definições do termo, dadas por alguns/algumas de seus criadores/as, ao longo das últimas décadas. Em 1994, quando a pesquisadora peruana-canadense Lady Rojas-Trempe, perguntou à atriz Ana Correa e ao ator Augusto Casafranca, se eles "concebem o teatro como uma arma para a transformação social" (Rojas-Trempe, 1994, p. 162), a atriz respondeu enfatizando a importância de o grupo ter conseguido garantir, a partir de 1982, uma maior dedicação aos processos de pesquisa e criação. Ao assegurarem o tempo necessário para os ensaios, eles se permitiram mergulhar em diversas matrizes das culturas andinas: uma acumulação sensível que o ator faz não só ideologicamente, ao buscar auxílio na ciência, na história ou na antropologia, mas uma acumulação na qual o ator faz na prática mesmo, treinando diariamente,

Hablamos de una acumulación sensible que el actor hace ya no sólo ideológicamente, para ayudarnos de la ciencia, la historia o la antropología, sino además por una acumulación que el actor hace en la práctica misma, entrenando diariamente, trabajando, saliendo a las calles, buscando personajes y observando. Entonces esa acumulación sensible ha desembocado en otra característica del actor profesional, que tiene la responsabilidad revolucionaria de ser bueno, de capacitarse para trabajar (Correa apud Rojas-Trempe, 1994, p. 162).

Através destas imersões os/as artistas do Yuyachkani passaram a articular suas criações não somente como espetáculo, mas principalmente, como ações cênicas 
que transitam entre linguagens e lugares que as práticas artísticas podem ocupar na sociedade. Um exemplo é o monólogo Rosa Cuchillo (2002) de Ana Correa, estruturado para ser realizado nos mercados andinos e nas feiras livres dos pequenos produtores rurais, que acontecem nos bairros das cidades peruanas.

A obra foi criada em um período de transição entre a renúncia do presidente Alberto Fujimori (1990-2000), o declínio das ações do grupo guerrilheiro Sendero Luminoso e o início da construção da atual democracia peruana. Neste momento delicado do país, muitos puderam pela primeira vez, sair em busca dos/as desaparecidos/as durante os mais de vinte anos de conflito armado. Um dos exemplos emblemáticos é o de Mamá Angélica que após diversas tentativas frustradas de encontrar o filho, funda na cidade de Ayacucho a Associação Nacional dos Familiares e Amigos dos Sequestrados e Desaparecidos do Peru (ANFASEP).

É a partir desses temas, somados à mitologia inca da novela Rosa Cuchillo, do escritor peruano Óscar Colchado, que Ana Correa construirá esta intervenção, a partir dos elementos que foram sendo coletados ao longo de sua pesquisa, como por exemplo, os paralelos encontrados com a sua história pessoal, a perda recente de sua mãe, os saberes das curandeiras indígenas que recebeu por intermédio da avó materna, as aproximações com as "danças" rituais, o repertório de movimentações dos animais "sagrados" e os ensinamentos ligados às técnicas de tai chi e kung fu. Enfim, acumulações sensíveis que não foram sintetizadas apenas narrativamente, mas, e prioritariamente, imageticamente através do corpo da criadora. Ao analisar as várias camadas da dramaturgia da obra, reconhecemos não apenas no texto, mas também nas ações, as motivações da personagem Rosa Cuchillo, ou Rosa Faca se traduzido para o português, a qual inicia sua trajetória

\begin{abstract}
contando que perdeu seus pais num terremoto e muito nova foi para uma chácara morar e trabalhar, até que um dia o filho do seu patrão bêbado tenta estuprá-la, mas ela puxa uma faca, que mantém sempre guardada próxima a ela, e o ameaça, ele foge, e depois disso todo o povoado onde Rosa vive fica sabendo do feito e seu nome que até então era Rosa Huanca vira Rosa Cuchillo. Também conta que teve um filho que se envolveu com os senderistas e que depois de procurado pela polícia nunca mais foi visto e que ela, de tanto buscar notícias de seu paradeiro, morreu de tristeza, mas que mesmo depois de morta não desiste de encontrar seu filho (Sousa, 2014, p. 52).
\end{abstract}

Ao longo dos processos, realizados durante os Laboratórios Abertos, os/as criadores/as do Yuyachkani compartilham suas experiências e maneiras de se apropriarem de modo particular do procedimento da acumulação sensível. A atriz Teresa Ralli (2008, p. 206), por exemplo, afirma que acumulação sensível é tudo o que a percepção acumula. Trata-se, portanto, de uma seleção do que se quer trabalhar, a partir de treinamento e improvisações, onde os atores e as atrizes elaboram um material pessoal que logo será reelaborado pelo grupo. Estas pequenas unidades são chamadas "eslabones" (elos, ligações), que são analisadas, provadas, algumas guardadas e outras convertidas em núcleos. Os elos se juntam e vão construindo uma corrente, assim vai surgindo a base de uma estrutura provisória que serve para eles/as seguirem trabalhando. 
A pesquisadora cubana Aimelyz Díaz, que participou de um dos Laboratórios Abertos, afirma em seu artigo Encuentro con Yuyachkani: experiencias de una convivencia escénica y humana que durante essa vivência, "Generar miradas, crear y habitar diversas texturas, evocar materiales ausentes, construer metáforas, fueron acciones que marcaron el proceso de acumulación sensible" (Díaz, 2016, p. 99).

Assim, acreditamos que por meio da acumulação sensível, é possível reconhecer que tudo o que surge ao longo de uma pesquisa prática criativa - um figurino, um poema, uma história de infância, um recorte de jornal, um encontro fortuito no ônibus, uma lembrança, uma proposta de cenário, uma sequência de músicas, uma partitura física, enfim, materiais diversos, - podem vir a compor uma ação cênica.

\section{Corpos e vozes encarnadas}

O diverso repertório de espetáculos, ações cênicas, demonstrações de trabalho do grupo que fazem parte da programação dos Laboratórios Abertos, contribuem significativamente para que as experiências nestas imersões sejam potencializadas, uma vez que através deles/as, se tornam visíveis os processos criativos de cada um/a de seus/as criadores/as e como eles se materializam em obras de diferentes naturezas. Como por exemplo, nas apresentações de peças e ações cênicas: Discurso de Promoción (2017), criação coletiva do grupo, que conta com a participação de diversos atores e atrizes convidados/as; Antígona (2000), unipersonal de Teresa Ralli; Adiós Ayacucho (1990) protagonizado por Augusto Casafranca; Rosa Cuchillo (2002), unipersonal de Ana Correa; No Me Toquen Ese Valse (1990), criação coletiva de Rebeca Ralli e Julián Vargas; Confesiones (2013), unipersonal de Ana Correa; Con-Cierto Olvido (2010) com Ana Correa, Augusto Casafranca, Débora Correa, Julián Vargas, Rebeca Ralli, Teresa Ralli e Cristian Atapaucar e por fim, Cartas de Chimbote (2015) com Teresa Ralli, Ana Correa, Débora Correa, Rebeca Ralli, Julián Vargas e Augusto Casafranca. Acompanhados das demonstrações de trabalho: Hijo de Perra, de Rebeca Ralli, La Rebelión de los Objetos, de Ana Correa e Vibraciones, de Julián Vargas.

Além de oficinas, como $O$ trabalho do ator sobre a sua voz, com Teresa Ralli e $O$ ator e a Máscara com Débora Correa e Augusto Casafranca; do Laboratório de Criação com Miguel Rubio Zapata e palestras sobre Criar em Grupo e O Grande Teatro de Paucartambo. Toda essa programação ajuda a acessar o repertório de um dos grupos mais relevantes da cena latino-americana contemporânea, através da aproximação das estratégias poéticas e políticas, compartilhadas por cada um/a de seus/suas criadores/as e como estas foram se transmutando e se reinventado, ao longo das últimas cinco décadas.

A presença dos muitos corpos e vozes que são revelados através de seus espetáculos, ações cênicas, demonstrações de trabalho, rodas de conversas e oficinas, permeiam todo o Laboratório e fazem parte do processo criativo dos/as participantes. Vale aqui destacar algumas delas, como é o caso ímpar de Afonso Cánepa, cidadão peruano, domiciliado em Quinua, de ocupação agricultor, preso pela guarda civil de seu povoado, torturado, queimado, mutilado, morto e declarado desaparecido, através do corpo do ator Augusto Casafranca em Adiós Ayacucho. 
Outro exemplo é a já citada Angélica Mendoza, Mamá Angélica, e os fragmentos das suas declarações sobre seu filho desaparecido durante a violência que tomou o Peru, a partir dos quais a atriz Ana Correa desenvolveu ações, que foram apresentadas em diversos espaços públicos das cidades andinas, onde se realizavam as Audiências Públicas da Comissão da Verdade e Reconciliação. Assim como José Maria Arguedas, homenageado por todo o grupo, "encarnado" por todos os atores e atrizes no espetáculo Cartas de Chimbote. Arguedas é, para além de escritor e antropólogo, um herói cultural do Peru, "[...] cuja vida e obra palpitam os fervores do nosso povo com seu sofrimento, sua alegria, seu prazer e, sobretudo, sua esperança" (Montoya, 2011, p. 11).

Além destas biografias reais, uma mitologia presente é a de Antígona, que através da magia do teatro, derrotada e morta, volta a nascer cada vez que é convocada, para seguir lutando contra as leis injustas dos homens. Teresa Ralli, que interpreta a personagem, convocou um grupo de mulheres, mães, irmãs e esposas de desaparecidos/as, para falar sobre este trabalho. Para Miguel Rubio Zapata (2008, p.65), ver e escutar na sala de ensaio a essas Antígonas peruanas e entrar em diálogo com as suas realidades cotidianas, de lutar por encontrar os corpos de seus/suas entes queridos/ as para dar-lhes sepultura, não somente fez com que eles entendessem o porquê deste trabalho, mas também deu a Teresa Ralli a base da presença física que, sem saber claramente, era o que ela estava buscando.

\section{Dimensões artístico-pedagógicas e suas possibilidades de reativação da potência política da arte na atualidade}

Acerca das dimensões artístico-pedagógicas, propostas nos Laboratórios Abertos e que permeiam o processo criativo do grupo, encontramos pistas nos apontamentos da crítica literária argentina Beatriz Sarlo (2016), feita a partir da constatação de uma virada subjetiva, que foi necessária para a reconstrução de narrativas, a partir de testemunhos, após o período da ditadura para que, para além da intimidade, a subjetividade também pudesse ter sua dimensão pública reconhecida nos processos de redemocratização, em países da América Latina. Esse giro demandou e continua demandando, um trabalho intenso de formação de modos de compartilhamento.

A pesquisadora brasileira Marta Haas na dissertação Práticas de resistência nas ações artístico-pedagógicas dos grupos Yuyachkani (Peru) e Ói Nois Aqui Traveiz (Brasil) (2017), também traz contribuições para este debate, quando enfatiza sobre as práticas pedagógicas desses dois grupos que,

formar-se artista-cidadão implica um trabalho constante, seja externa ou internamente, na busca por transformação. A partir do encontro com o outro, da construção em grupo e comunidade, o processo contínuo de ação sobre si se revela formador de novas subjetividades. O processo de formação vai além do desenvolvimento de potencialidades individuais, ele se afirma como potência coletiva. Pensar coletivamente e agir em prol de um compromisso ético que se assume quando nos percebemos parte de um coletivo - seja o pequeno coletivo do grupo teatral, ou o grande coletivo que representa a nossa sociedade (Haas, 2017, p. 156). 
Esse viés é também debatido por Eleonora Fabião, quando declara que "pedagogia [...] é ensinar a ver todas as coisas sob o ângulo do conflito, da transformação, do desvio, da alteração. É também, aos olhos de Brecht, a arte de transformar e multiplicar seus próprios meios para saber algo do mundo e agir sobre ele" (Fabião, 2016, p. 177). No texto Performance, teatro e ensino: poéticas e políticas da interdisciplinaridade (2012), Fabião compartilha que como professora-performer, seu trabalho é propor e vivenciar experiências que visam desenvolver e integrar as "capacidades orgânicas, criativas, comunicacionais do atuante (performer, cidadão, sujeito histórico, vivente) e visam seu fortalecimento através do aumento de agilidade, flexibilidade e disponibilidade" (Fabião, 2012, p. 66). A pesquisadora frisa que independentemente do espaço e do modo como aconteçam

a sala de aula, o palco, a rua, a folha de papel, o corpo são dimensões de uma mesma busca: fundar espaços de reflexão e criação onde proponho que nos perguntemos não apenas o que seja "arte contemporânea", mas o que queremos, contemporaneamente, que a arte seja. (Fabião, 2012, p. 61)

Nesta perspectiva, os Laboratórios Abertos tornam evidente a necessidade de não apenas observar a potência política da arte, a partir da maneira com que o Yuyachkani dá visibilidade e protagonismo aos corpos e vozes excluídas, marginalizadas, mas também, participar e contribuir com este processo de criação de ações e atos cênicos, poéticos e políticos, à maneira de cada participante, a partir de suas urgências e emergências.

No último dia do Laboratório Aberto de 2017, por exemplo, nós, autoras deste artigo, improvisávamos com máscaras, a partir de ações vivenciadas e criadas ao longo dos dias de trabalhos (ver figura 2) e decidimos que precisávamos mostrar ao grupo e aos colegas do Laboratório a realidade que estávamos vivendo naquele momento no nosso país. Assim, fizemos nossa intervenção. Tiramos as nossas máscaras e enquanto uma de nós "dissimulava" ironicamente a coreografia do Segure o Tchan, a outra tomou o microfone exclamou alguns fatos da atual realidade brasileira: o golpe de estado que vivíamos/vivemos com o impeachment da presidenta Dilma, eleita democraticamente; os retrocessos que vivíamos/vivemos pelas tomadas de decisões do ilegítimo ex-presidente, o golpista Michel Temer, tanto no nível da educação, da economia e da saúde; dos direitos recentemente usurpados dos/as trabalhadores/as que foram conquistados com décadas de luta; bem como a realidade violenta que assolava/assola as "minorias" do nosso país, dentre mulheres, crianças, indígenas, transexuais, travestis, homossexuais, lésbicas, negros e negras que são assassinados/ as covardemente, diariamente.

Mal sabíamos que meses depois de regressar ao Brasil, passaríamos por momentos terríveis de censura na arte, de proibições de corpos nus em cena, de perseguições de artistas, de prisões injustificadas e assassinatos políticos. O Laboratório terminou em silêncio, após algumas declarações da estudante e artista brasileira Maite Baraybar, ao finalizar esse momento tão significativo para nós, mulheres brasileiras, presentes no Laboratório. 


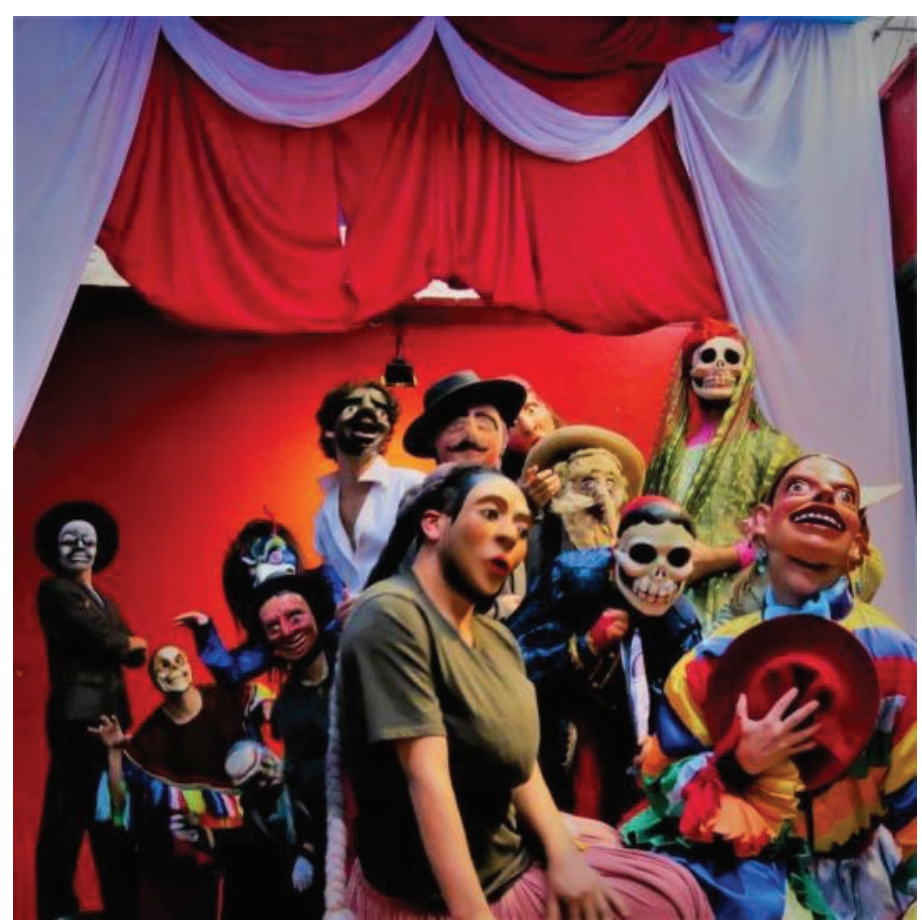

Figura 2- $9^{\circ}$ Laboratório Aberto- Encontro Pedagógico do Grupo Yuyachkani. Fonte: Claudia Vanesa Figueroa. Data: 11 de agosto de 2017.

Ao final, esse momento de reativação da nossa potência política, do desejo de não se calar, nos fez lembrar uma passagem significativa da primeira viagem do grupo Odin Teatret, dirigido por Eugênio Barba ao Peru, em Ayacucho no ano de 1978, no célebre Encontro de Teatro de Grupos organizado pelo grupo teatral Cuatrotablas. Miguel Rubio Zapata (2011, p.181), narra que havia sido difícil para o grupo tomar a decisão de ir a este encontro, no momento que se fazia uma parada nacional de quarenta e oito horas, contra o regime militar em Lima. A ideia do Yuyachkani era participar dessa parada nacional com ações na rua, mas eles acabaram viajando para o evento e em Ayacucho, se sentindo culpados, se perguntaram: "Não vamos dizer nada?", enquanto Eugênio Barba fazia uma conferência dizendo que com teatro não se faz revolução.

Conforme Miguel Rubio Zapata (2011), mesmo sem ter um trabalho teatral para apresentar no encontro, os integrantes do grupo não se calaram, cantaram diversas canções revolucionárias e que apesar de todas as objeções e negações, naquele momento fios condutores de uma corrente invisível foram criados com muita força entre eles, o Odin e Eugênio Barba. A nossa pergunta ao final do Laboratório foi exatamente essa: "Não vamos dizer nada?" e como o Yuyachkani em Ayacucho, nós não nos calamos e gritamos com nossos corpos, vozes e espíritos a realidade atual do nosso país. 


\section{Referências}

DÍAZ, Aimelys. Encuentro con Yuyachkani, experiências de una convivência escénica y humana. In: Revista Conjunto n. 181, 2016, p. 94-99.

FABIÃO, Eleonora. Performance, Teatro e Ensino: poéticas e políticas da interdisciplinaridade. In: TELLES, N.; FLORENTINO, A. (Org.). Cartografias do Ensino do Teatro. Uberlândia: Editora da Universidade Federal de Uberlândia, 2009. p. 61-72.

HAAS, Marta. Práticas de Resistência nas Ações Artístico-Pedagógicas dos Grupos Yuyachkani (Peru) e Ói Nóis Aqui Traveiz (Brasil). 2017. Dissertação (Mestrado em Educação), Faculdade de Educação, Universidade Federal do Rio Grande do Sul, Porto Alegre, 2017.

MONTOYA, Rodrigo. Cien Años del Perú y de José María Arguedas-1911-2011. Lima: Editora Universidad Ricardo Palma, 2011.

ROJAS-TREMPE, Lady. "Yuyachkani y su trayectoria dramática en Perú: entrevista a Ana Correa y Augusto Casafranca" In: Latin American Theatre Review 28. 1, Fall p. 159-165, 1994.

SARLO, Beatriz. Paisagens imaginárias: intelectuais, arte e meios de comunicação. São Paulo: Editora da Universidade de São Paulo, 2016.

SOUSA, Thaís Helena Rissi de. Yuyachkani: teatro e performance enquanto registo e memória na latino-américa. 2014. Dissertação (Mestrado em Artes) - Instituto de Arte e Comunicação Social, Universidade Federal Fluminense, Niterói, Rio de Janeiro, 2014.

ZAPATA, Miguel Rubio. Raices y Semillas - Maestros y caminos del teatro em América Latina. Argentina: Ediciones del Boulevard, 2011.

ZAPATA, Miguel Rubio. El Cuerpo Ausente - Performance Política. Lima: Biblioteca Nacional del Perú, 2008.

ZAPATA, Miguel Rubio. O grande teatro de Paucartambo. São Paulo, Sala Preta, v.16, n.1, p. 5-25, 2016.

Recebido em: 23/07/2019

Aprovado em: 10/09/2019 